\title{
Celebrating IYPT 2019 - The UNESCO International Year of the Periodic Table
}

\author{
By Vladimir Shiltsev
}

As 2019 draws to a close, we should look back to the year 1869, when Dmitrii Mendeleev first proposed the periodic system of the elements, a framework that has truly become a common language for science. In December 2017, the United Nations General Assembly proclaimed 2019 as "the International Year of the Periodic Table of Chemical Elements [IYPT2019] to enhance global awareness of, and to increase education in, the basic sciences..."

Mendeleev's table not only classified the known elements, but enabled him to predict those that were missing, along with their physical and chemical properties. It also paved the way for many other discoveries such as those of the noble gases by William Ramsay and Lord Rayleigh (1904 Nobel Prize in Chemistry) and the first radioactive elements by Marie Curie, along with her husband Pierre (1903 Nobel Prize in Physics, 1911 Nobel Prize in Chemistry).

More recently, accelerators have played an important part in filling in the periodic table as we know it now. All but two trans-uranium elements, from Neptunium (93) to Oganesson (118), have been discovered at the cyclotron accelerator facilities in the US, USSR/Russia, Germany, and Japan. The 1951 Nobel Prize in Physics went to Glen Seaborg and Edwin McMillan for the discovery of transuranic elements, while Ernest O. Lawrence, a pioneer of modern particle accelerators, won the Nobel Prize in Physics in 1939 for his invention of the cyclotron.

And in recognition of the 150th anniversary, the Physical Review journals have collected relevant papers on various aspects of these discoveries. Those papers published in the Physical Review journals have been made free-to-read: https://journals.aps.org/prl/transuranium-elements-and-the-physical-review.

The IYPT2019 web site has an impressive map of hundreds of events and celebrations world wide, organized by various universities, associations, organizations, and institutions. For example, Fermilab and CERN had celebrated the IYPT, organized colloquia, seminars and lectures on the Periodic Law, its history and influence.

Fermilab's celebration of the International Year of the Periodic Table on June 26, 2019, started with a piece of cake shaped as the Periodic Table of elements. The celebration continued with the premiere of a Fermilab video on the Periodic Table and a show-and-tell poster on the UNESCO IYPT. It capped off with the Colloquium presentation by Princeton University's Michael Gordin, who explored what Mendeleev did in 1869 , how it related to what came before and after, and a few of the myths that have accumulated around his work (video).

On September 12, 2019, the President of the European Physical Society (EPS) Petra Rudolf inaugurated the Mendeleev Museum-Archive, at the University of Saint Petersburg as the EPS Historic Site and ceremonially unveiled a commemorating plaque in a ceremony attended by many scientists, chemists and physicists, members of EPS and APS. 
I was part of the IYPT2019 celebrations at the Tyumen State University in Russia (Mendeleev's birthplace) and the INFN Ferrara and the INFN Padova in Italy in which I explained what Mendeleev's path to the 1869 discovery and presented in a broader perspective of his Nature-Philosophy views and works, which include theory and investigations of solutions, such as alcohol in water, studies of rarified gases and discovery of supercritical fluids.

Two remarkable commemorating events took place in Italy this Fall. First, the 2019 Festival della Scienza in Genova (Oct. 24 - Nov.4) - very popular annual science-pop event - came under the main theme of "The Elements" to celebrate the occasion is the IYPT2019.

And on November 6 and 7, 2019, the Italian Physical Society (SIF) in collaboration with the Italian Chemical Society (SCI) organized "Passion for Science: New Elements and New Materials" International Symposium on the occasion of the International Year of the Periodic Table of Chemical Elements (IYPT2019).

The celebrations all come to a close at a ceremony in Tokyo on December 5, 2019. Attendees will be treated to presentations from representatives of the International Union of Pure and Appled Chemistry and the International Union of Pure and Applied Physics, scientists involved in the discovery of new elements, and observations on what lies in the future for the periodic table.

\section{Acknowledgements}

I thank those who organized various IYPT2019 events, including Chris Stoughton, Reidar Hahn, Chris Quigg, Christopher Beard and Lisa Lopez (Fermilab), Olga Zunde and Vladimir Novoselov (Tyumen), Igor Dmitriev (St. Petersburg), Frank Zimmermann and Michael Benedikt (CERN), Stefania Vecchi (Ferrara), Marco Pallavicini (Genova), Tommaso Dorigo (Padova), and Luisa Cifarelli and Aldo Rodo (Bologna).

The author is a Distinguished Scientist at Fermilab, Past Chair of the APS Division of Physics of Beams, former member of the APS Committee on International Scientific Affairs and the Executive Committee of the Forum on International Physics. He is a Fellow of APS and AAAS and recipient of the 2019

Nishikawa Prize, the 2016 Gamow Award, the 2004 EPS Accelerator Prize.

\section{Further Reading}

More on the UNESCO IYPT2019 can be found at https://www.iypt2019.org/

Special Physical Review Collection: https://journals.aps.org/prl/transuranium-elements-and-thephysical-review 